\title{
Effect of Flow Regime on the Architecture of a Pseudomonas fluorescens Biofilm
}

\author{
Maria Olivia Pereira, ${ }^{1}$ Martin Kuehn, ${ }^{2}$ Stefan Wuertz, ${ }^{3}$ Thomas Neu, ${ }^{4}$ \\ Luis F. Melo ${ }^{1,5}$ \\ ${ }^{1}$ University of Minho, Centro de Engenharia Biológica/IBQF, 4710-057 Braga, \\ Portugal \\ ${ }^{2}$ Institute of Water Quality Control and Waste Management, Technical \\ University of Munich, Am Coulombwall, D-85748 Garching, Germany \\ ${ }^{3}$ Department of Civil and Environmental Engineering, University of \\ California, Davis, One Shields Avenue, Davis, California \\ ${ }^{4}$ Institute of Inland Water Research Magdeburg, UFZ Centre for
}

Environmental Research, Leipzig-Halle, Brueckstr. 3A, 39114 Magdeburg,

Germany

${ }^{5}$ Faculty of Engineering of the University of Porto, Chemical Engineering

Department, LEPAE, 4200-465 Porto, Portugal; telephone: +351 225081588;

fax: +351 225081449; e-mail: Imelo@fe.up.pt

Received 17 August 2001; accepted 8 November 2001

\begin{abstract}
A comparison of the effects of laminar versus turbulent flow regime on the characteristics of a singlespecies biofilm is presented. The study was carried out by growing Pseudomonas fluorescens biofilms in a flow cell and studying the different layers of the biological matrix with a confocal laser-scanning microscope. The following conclusions were obtained: i) a higher concentration of cells was found in the upper layers of the microbial films than in their inner layers, regardless of the flow regime; ii) the fraction of cells in the overall biofilm mass decreased with time as the film grew; and iii) under laminar flow the total number of cells was higher than in biofilms formed under turbulent flow, but the latter had a higher number of cells per unit volume. Such conclusions, together with the fact that the biofilms were more dense and stable when formed in contact with turbulent flows, favor the design of more compact and efficient biofilm reactors operating in turbulent conditions. () 2002 Wiley Periodicals, Inc. Biotechnol Bioeng 78: 164-171, 2002; DOI 10.1002/bit.10189

Keywords: biofilm architecture; hydrodynamic conditions; laminar and turbulent flows; CLSM image analysis; biovolumes; Pseudomonas fluorescens
\end{abstract}

\section{INTRODUCTION}

Bacterial attachment to submerged solid surfaces and subsequent microbial growth and exopolymer production lead to the formation of biofilms. In urban and industrial systems such as drinking water networks, paper manufacturing plants, and heat-exchange operations, as well as in the medical field, biofilms generally give rise to undesired problems that affect production processes, product quality, and human health. Conversely, biofilms can be beneficial when used in biore-

Correspondence to: L. F. Melo

Contract grant sponsor: PRAXIS

Contract grant numbers: 2/2.1/BIO/37/94; BD/3242/94 actors for wastewater treatment and for the production of desired compounds (Characklis and Marshall, 1990).

The physical architecture of bioflim can be defined as the spatial arrangement of the biomass (containing microbial cells and the extracellular matrix they produce) and the interstitial spaces or channels (de Beer and Schramm, 1999; Okabe et al., 1998; Sandford et al., 1996). In the last decade, investigations revealed that biofilms are often non-homogeneous and highly hydrated microsystems containing biomass layers and clusters, as well as voids or pores (de Beer and Schramm, 1999), which are not necessarily uniform in time or space. The complexity and variability of such biological matrices influence the microbial activity as well as biofilm physical properties and significantly increase the difficulty of biofilm modelling. As a consequence, the knowledge of the internal structure of microbial films is essential for understanding biofilm activity and for timely applying appropriate measures to either control the growth of unwanted biofilms or improve the performance of beneficial biofilms.

One of the most important factors affecting biofilm structure and activity is the velocity field of the fluid in contact with the attached microbial layer. Biofilm reactors, for example, may operate under quite different hydrodynamic conditions, from laminar flow in submerged filters to turbulent flow in air-lift reactors; furthermore, changes in the fluid velocity occur often during the operation of industrial reactors. The macroscopic effects caused by different flow rates (different velocities and/or different flow regimes) have been the subject of a number of reports on the properties and activity of biofilms (Bott, 1995; Characklis and Marshall, 1990; Vieira et al., 1993; Wijeyekoon et al., 2000). The general conclusion is that when biofilms grow under turbulent 
flow, the higher the velocity the thinner and denser (with higher content of extracellular polymeric substances) the biofilm will be for Brading et al. (1995) compared Pseudomonas fluorescens biofilms formed at different flow velocities, under laminar regime, and found that more exopolysaccharides were produced by the biofilm bacteria when subject to higher fluid velocities. They also concluded that for low substrate concentrations (100 mg of glucose per litre or less), microbial growth within the biological matrix was flow dependent. However, some authors did not find any effect of shear stress when the microbial film was subject either to high or to low substrate loading rates (Peyton, 1996), possibly under laminar flow (information not given explicitly). Wijeyekoon et al. (2000) studied mixed population biofilms under laminar (from $R e=100$ to $R e=2000$ ) and turbulent flow $(R e=5500)$, and reported that the latter had a remarkably higher cell density with the exopolysaccharides mainly concentrated in the base of the film.

Biofilm thickness and density have an obvious influence on the microbial metabolism in the film because they may introduce diffusional limitations as well as affect the composition of the microenvironment surrounding the cells within the matrix. The effects of the hydrodynamic parameters, particularly the type of flow regime and the concentration and spatial distribution of microbial cells are not well understood. When going from laminar to turbulent flow patterns, not only does the velocity increase but so does turbulence, introducing new forms of energy dissipation that affect the surfaces in contact with the flow field. In turbulent flow, an increase in the fluid velocity means an increase both in the shear stress and in the intensity of the turbulent eddy mechanisms (Schlichting, 1979). There will also be variations in the angle by which the shear forces are applied to the biofilm surface in a turbulent system, possibly affecting the developing architecture (cell cluster formation). The biofilm may oscillate once a critical flow velocity has been reached (Lewandowski and Stoodley, 1995).

The application of confocal laser scanning microscopy (CLSM) to biofilm research, mainly when combined with a range of staining fluorescent techniques, provides an important, versatile, and effective tool to analyze the composition and structure of hydrated biofilms in situ non-destructively and in real time (Lawrence et al., 1998b, 2001; Lawrence and Neu, 1999) as well as the cellular viability and distribution within the biofilm. CLSM also allows the horizontal and vertical optical thin sectioning of hydrated biofilms, making possible the quantification of various parameters of the three-dimensional (3D) biofilm structure by digital image processing (Kuehn et al., 1998; Lawrence et al., 1998a).

The aim of the present study was to investigate how the flow regime (laminar or turbulent) could affect quantitative parameters, such as cell concentration (measured as "biovolumes"), thickness and biomass density, describing the structure of Pseudomonas flu- orescens biofilm developed in a flow cell reactor. The parameters were calculated from horizontal and sagittal images acquired with a CLSM. A single-species biofilm was chosen to avoid the additional difficulties brought by complex population dynamics and multiple substrate utilizations. The study involved not only the comparison of steady-state biofilms formed under different flow regimes but also the monitoring of cell density changes with time during biofilm formation.

\section{MATERIAL AND METHODS}

\section{Microorganism and Cell Growth}

The microorganism used to produce biofilm was the Gram-negative aerobic bacterium Pseudomonas $f(u-$ orescens. These bacteria are good biofilm producers, and their optimal growth conditions are $27^{\circ} \mathrm{C}, \mathrm{pH} 7$, and glucose as the carbon source (Oliveira et al., 1994).

A culture of $P$. fluorescens was grown in a 1-L glass fermenter (fermenter 1), suitably aerated and agitated, continuously fed $\left(10 \mathrm{~mL} \cdot \mathrm{h}^{-1}\right)$ with a sterile nutrient solution consisting of $5 \mathrm{~g}$ glucose $\mathrm{L}^{-1}, 2.5 \mathrm{~g}$ peptone $\mathrm{L}^{-1}$, and $1.25 \mathrm{~g}$ yeast extract $\mathrm{L}^{-1}$ in phosphate buffer at $\mathrm{pH} 7$ $\left(0.2 \mathrm{M} \mathrm{Na}_{2} \mathrm{HPO}_{4}\right.$ and $\left.0.2 M \mathrm{NaH}_{2} \mathrm{PO}_{4}\right)$. The culture was used to continuously inoculate $\left(10 \mathrm{~mL} \cdot \mathrm{h}^{-1}\right)$ a $3-\mathrm{L}$ vessel (fermenter 2) containing sterile water, aerated and agitated. This fermenter was fed with the buffered medium described above $\left(17 \mathrm{~mL} \cdot \mathrm{h}^{-1}\right)$, and the bacterial culture was diluted with filtrated tap water $\left(1.7 \mathrm{~L} \cdot \mathrm{h}^{-1}\right)$ to obtain a suspension with $6 \times 10^{7}$ cells $\mathrm{mL}^{-1}$ and $20 \mathrm{mg} \cdot \mathrm{L}^{-1}$ of glucose. The bacterial suspension was pumped up, passing through the flow cell reactors and back to the fermenter 2 (Fig. 1).

\section{Flow Cell Reactor}

The flow cell reactor used in this work, illustrated in Figure 1, has a semi-circular cross-section and contains seven removable slides (stainless-steel slides glued on rectangular pieces of Perspex that properly fit in the apertures of the flow cell) that allow sampling of biofilm at desired time intervals. Each slide can be removed separately in such a way that it does not disturb the biofilm formed on the others and does not require the stoppage of the flow (the flow cell has on its circular surface, located between each two adjacent slides, several exit ports for the biological fluid that permit the continuous flow of the fluid even when the slide is removed).

The slides were polished with sandpaper (P-1000) and polishing cream, degreased with detergent, rinsed with distilled water, and immersed in ethanol before use. The flow cell reactor was sterilized by passing a solution (10 $\mathrm{mL} \cdot \mathrm{L}^{-1}$ ) of sodium hypochlorite with $13 \%$ of active chlorine, through it and rinsing it with water. Dimensions of each flow cell were as follows: length $=50 \mathrm{~cm}$; diameter $=1.5 \mathrm{~cm}$; Area of each slide $=2.34 \mathrm{~cm}^{2}$. 


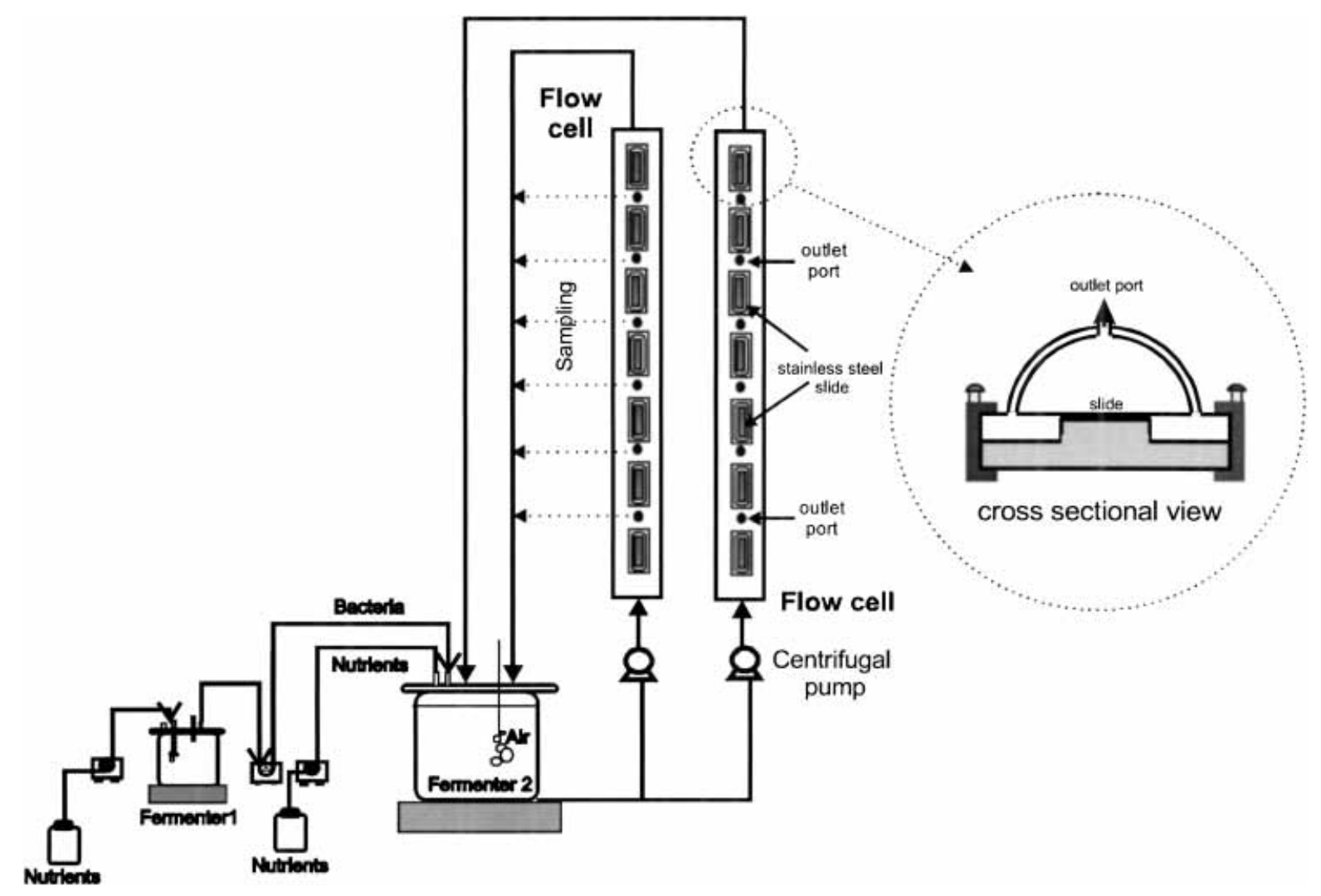

Figure 1. Experimental set-up, including a continuous bacterial culture system (fermenter 1 and 2) and two flow cells of semicircular cross-section containing the removable test slides.

\section{Biofilm Growth}

Biofilms were formed by recirculating the bacterial suspension, obtained from the second fermenter at $27^{\circ} \mathrm{C}$ and $\mathrm{pH} 7$, using two similar flow cell reactors. One of them was used to promote laminar flow (Reynolds number: $R e=2000$, fluid velocity around $\left.0.21 \mathrm{~m} \cdot \mathrm{s}^{-1}\right)$ and the other turbulent flow $(R e=5500$, fluid velocity approximately $\left.0.51 \mathrm{~m} \cdot \mathrm{s}^{-1}\right)$.

At fixed time intervals, one biofilm covered slide was carefully removed from each cell, replaced with a clean slide, and immediately prepared for further analysis. The first slides to be removed were those on the top of the flow cells (near the outlet).

\section{Biofilm Properties}

\section{Biofilm Thickness}

The biofilm thickness and the spatial distribution of the bacteria in the biological layer at different times during biofilm growth were investigated using CLSM. For this purpose, the in situ hydrated biofilm formed on the slides was stained using the staining kit LIVE/DEAD obtained from Molecular Probes Inc. (Eugene, OR). The procedure has been described elsewhere in detail (Neu and Lawrence, 1997). To stain glycoconjugates within the biofilm fluor conjugated lectins were used.
The TRITC-labeled lectins included: Canavalia ensiformis, Triticum vulgaris, and Limulus polyphemus (Sigma, St. Louis.). Application of lectins has been described previously (Lawrence and Neu, 1999).

\section{Confocal Laser Scanning Microscopy}

CLSM observations were made with a TCS 4D (Leica, Heidelberg, Germany) attached to an inverted microscope and equipped with an argon-krypton laser. The microscope was controlled by ScanWare Version 5.10 (Leica). Images were collected with a 60X $0.9 \mathrm{NA}$ water immersion lens (Olympus, Tokyo, Japan) in $\mathrm{Z}$ direction for subsequent image analysis and several images were acquired. In the present case, the staining procedures allowed the visualisation of cells only, but not of the biofilm extracellular polymers.

\section{Deposit Dry Mass}

The deposit dry mass was obtained by weighing the slides before and after biofilm formation. In the beginning of each experiment, i.e., before being inserted in the flow cells and after being degreased, rinsed, and dried, the stainless-steel slides were identified and weighed, with an accuracy of $0.001 \mathrm{~g}$. Once a steady-state deposit was formed (after approximately $8-10$ days), the mass of the 
slides plus attached deposit was determined after being dried to constant mass under steady conditions $(24 \mathrm{~h}$; T $=80^{\circ} \mathrm{C}$ ). Deposit dry mass accumulated on the several stainless steel slides was thus calculated as the difference between the two respective weights and expressed in kilograms per $\mathrm{m}^{2}$ of surface area of the stainless steel slide. The results here presented are the average of three or more measurements.

\section{Image Analysis}

The on-line sequential collection of digital images of the CLSM optical thin sections was used to quantitatively determine such parameters as biofilm thickness, cell biomass at various depths, and biovolumes over time. Details of the image acquisition and processing procedures can be found in Kuehn et al. (1998). Cell biomass refers to the accumulation of $P$. fluorescens on each horizontal section area and is expressed as bacterial cell area, i.e., as the fraction of the area covered by bacteria on each confocal plane in relation to a lens-dependent reference area $\left(2.53 \times 10^{-8} \mathrm{~m}^{2}\right)$. The biovolume of each biofilm stack was calculated by numerical integration of all the bacterial cell areas obtained by following the trapezoidal rule and is, thus, representative of the amount of cells within the biofilm.

\section{Scanning Electron Microscopy (SEM) Observations}

During the experiments a few deposit-covered stainlesssteel slides were observed by SEM. Prior to SEM observations, the biofilm samples were dehydrated through an absolute ethanol series to $100 \%$ and dried in a desiccator for 3 days. The samples were sputter-coated with gold and examined with a Leica S360 scanning electron microscopy at $10-15 \mathrm{kV}$. The slides were not fixed because the fixation procedures involve the use of chemicals that tend to react with some of the components of the biological matrix, as documented by Azeredo et al. (1999), hence modifying the real biofilm structure.

\section{RESULTS}

CLSM observations of the slides show that they were substantially covered with bacteria and colonies since the first day of contact with the microbial suspension (Fig. 2) for both flow regimes, laminar and turbulent. These observations also show that the bacterial colonization was very heterogeneous, varying from dispersed attached cells to bacterial clusters. The live/dead tests did not indicate any significant number of dead cells in the biofilm. This could be expected because the biofilms are quite thin and, therefore, mass transfer limitations are not significant.

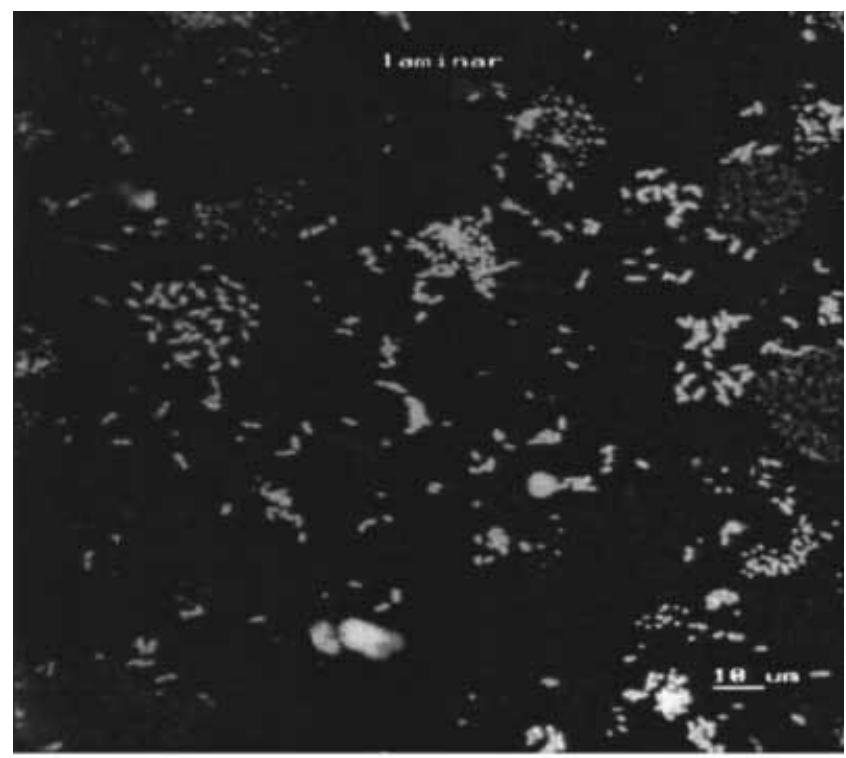

(a)

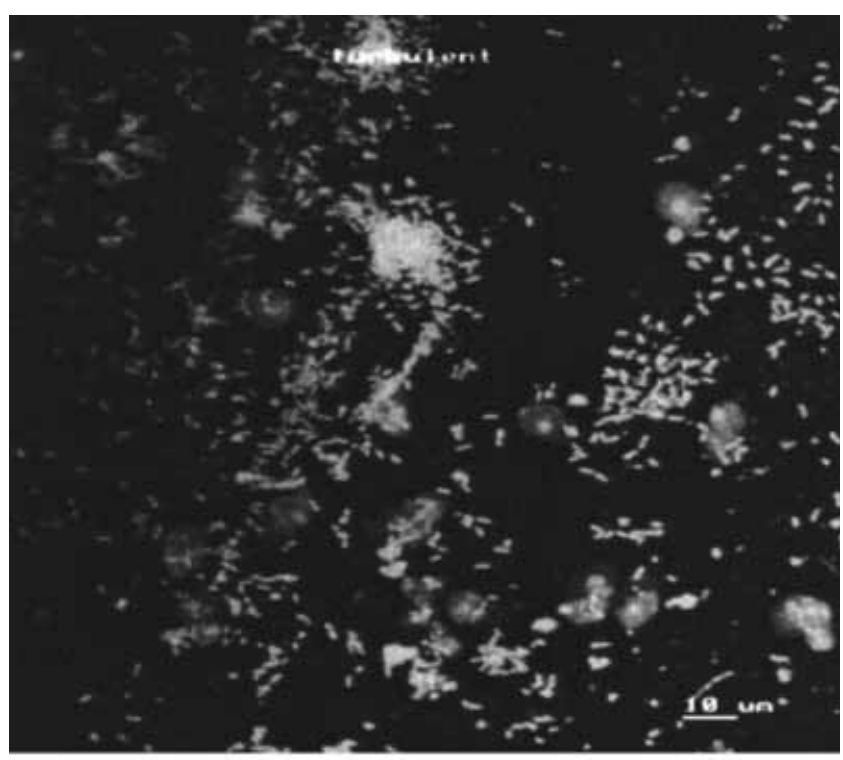

(b)

Figure 2. CLSM micrograph of a 1-day-old Pseudomonas fluorescens biofilm formed on stainless-steel slides under laminar (a) and turbulent (b) conditions. Maximum intensity projection, bar $=10 \mu \mathrm{m}$.

Figure 3 is a representative pattern of the microbial colonization of two biofilm stacks, at day 7 , formed under turbulent and laminar flow. The biovolume in each stack corresponded to the numerically integrated volume occupied by the cells. In general, the CLSM images obtained in this study revealed that the greatest amount of cellular biomass was concentrated in the upper regions of the biofilm.

Table I presents the biofilm thickness and biovolume values obtained under different flow conditions. The biovolume values presented here are the average volumes of the cellular material within all stacks measured for each flow condition and time interval. 


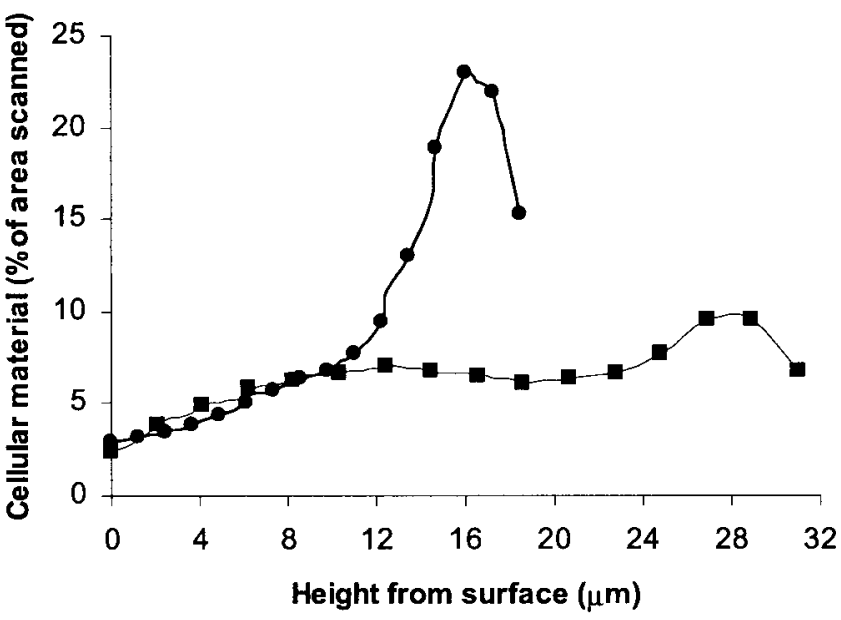

Figure 3. Distribution of cellular material versus z-scan position of a 7-day aged biofilm formed under turbulent $(\boldsymbol{\square})$ and laminar $(\bullet)$ conditions (illustrative example). $\%$ cellular material $=\%$ area occupied by the cells in the scanned reference area.

Higher thicknesses were obtained at the lowest velocity (laminar flow), although with significant variability in time. On the contrary, the biofilm thicknesses measured in the turbulent assay were more stable.

Regarding the biovolumes, higher values were obtained in the laminar flow test, meaning that there were more cells in the laminar biofilm than in the turbulent situation. The fluctuations in biovolumes are also more pronounced in the biofilm formed under laminar flow conditions. The results were statistically tested, by using the Student's $t$ test distribution, to assess whether the differences between the experimental values obtained under the different flow regimens could be considered significant. The effect of the flow regimen both on thicknesses and biovolumes was found to be statistically significant because the confidence level for 3 degrees of freedom was higher than $90 \%$.

The change in dry biomass (per unit area of the slides) over time, given in Figure 4, confirms the significant fluctuations of the growth curve under laminar flow caused by sloughing off and re-growth phenomena, as well as the more stable growth trend in the turbulent flow case. Table II presents the mass of cells per unit

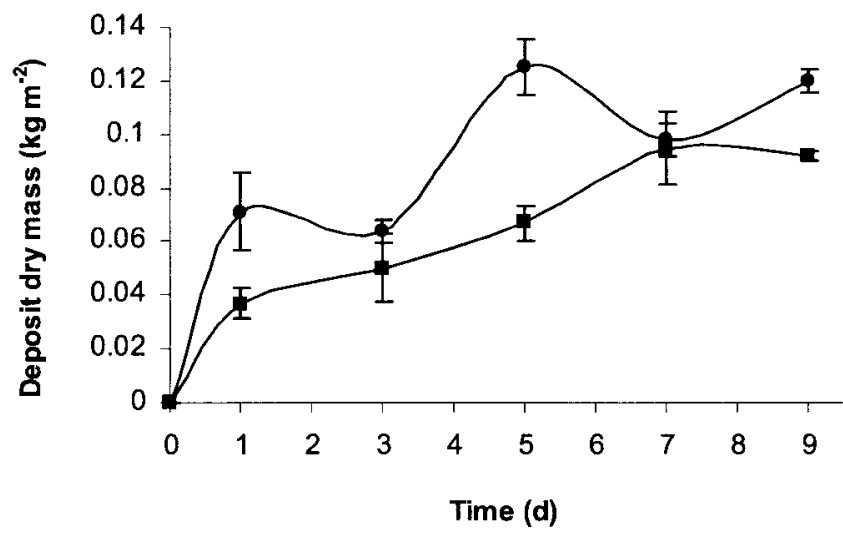

Figure 4. Deposit dry mass as a function of time; ( $)$ laminar flow, (ם) turbulent flow; bars mean the standard deviation from the mean (n $=4)$. Obs: This mass is somewhat higher than the biofilm dry mass due to the presence of inorganic matter.

mass of dry deposit, which was calculated from Table I and Figure 4 by multiplying the biovolumes by the density of each cell (approximately, $1000 \mathrm{~kg}^{-3}$ ) and dividing them by the deposit dry mass of the same reference area. Whereas in laminar flow this parameter does not display a stable trend due to fluctuations in the attached biomass, it can be seen that in turbulent flow the fraction of bacterial cell mass in the dry biofilm decreases steadily with time.

Additionally, the average bacterial cell area per unit volume of wet biofilm was calculated in every biofilm stack, with the purpose of looking at the average spatial concentration of cells within both biofilms overtime. For turbulent flow, the average ratio cells/biofilm volume was found to be roughly constant, fluctuating between $1.0 \times 10^{-5}$ and $1.5 \times 10^{-5} \mu \mathrm{m}^{2} \cdot \mu \mathrm{m}^{-3}$, whereas for laminar flow this ratio decreased from $1.0 \times 10^{-5}$, at day 1 to $0.28 \times 10^{-5} \mu \mathrm{m}^{2} \cdot \mu \mathrm{m}^{-3}$ at day 9 . Therefore, in turbulent flow, the cellular concentration per unit volume of wet biofilm was higher than in laminar flow and did not show significant changes with time.

Staining of the biofilm samples with the available lectins did not show any significant glycoconjugate signal. The lectins used were specific for D-glucose, $N$ acetyl-D-glucosamine, D-mannose, sucrose, fructose

Table I. Biofilm thicknesses and biovolumes under different flow conditions as a function of time; in brackets the standard deviation from the mean value.

\begin{tabular}{|c|c|c|c|c|}
\hline \multirow{2}{*}{$\begin{array}{c}\text { Biofilm Age } \\
\text { (d) }\end{array}$} & \multicolumn{2}{|c|}{ Laminar flow $(R e=2000)$} & \multicolumn{2}{|c|}{ Turbulent flow $(\operatorname{Re}=5500)$} \\
\hline & Thickness $(\mu \mathrm{m})$ & Biovolume $\left(\mu \mathrm{m}^{3}\right)$ & Thickness $(\mu \mathrm{m})$ & Biovolume $\left(\mu \mathrm{m}^{3}\right)$ \\
\hline 1 & $21( \pm 7)$ & $31523( \pm 16815)$ & $17( \pm 3)$ & $23670( \pm 6819)$ \\
\hline 3 & $33( \pm 15)$ & $69117( \pm 10383)$ & $21( \pm 5)$ & $27381( \pm 9149)$ \\
\hline 7 & $28( \pm 12)$ & $49715( \pm 21961)$ & $22( \pm 8)$ & $43894( \pm 5018)$ \\
\hline 9 & $54( \pm 6)$ & $63181( \pm 21827)$ & $24( \pm 12)$ & $36596( \pm 10574)$ \\
\hline
\end{tabular}

A paired comparison test using Student's $t$ test distribution was perfomed (Daniel, 1987) considering time as the independent variable. In one of the comparison tests, biofilm thicknesses under laminar and turbulent flow were the dependent variables. The same comparison procedure was applied to the differences between biovolumes in laminar and turbulent cases. 
Table II. Cell wet mass per deposit dry mass, as a function of time; in brackets the standard deviation from the mean value.

\begin{tabular}{ccc}
\hline Biofilm Age & $\begin{array}{c}\text { Laminar flow } \\
(R e=2000)\end{array}$ & $\begin{array}{c}\text { Turbulent flow } \\
(R e=5500)\end{array}$ \\
\hline$(\mathrm{d})$ & $\mathrm{Kg}_{\text {cell }} / \mathrm{Kg}_{\text {dry deposit }}$ & $\mathrm{Kg}_{\text {cell }} / \mathrm{Kg}_{\text {dry deposit }}$ \\
\hline 1 & $0.0172( \pm 0.0018)$ & $0.0247( \pm 0.0037)$ \\
3 & $0.0418( \pm 0.0108)$ & $0.0212( \pm 0.0057)$ \\
7 & $0.0195( \pm 0.0065)$ & $0.0179( \pm 0.0026)$ \\
9 & $0.0204( \pm 0.0033)$ & $0.0154( \pm 0.0030)$ \\
\hline
\end{tabular}

(Canavalia ensiformis), $N^{\prime} N^{\prime}$-diacetylchitobiose, $N^{\prime} N^{\prime} N^{\prime}$ triacetylchitobiose (Triticum vulgaris) $N$-acetylneuraminic acid, D-glucuronic acid (Limulus polyphemus). This result indicates that the bacterial strain as grown and used in this study does not produce a polymer with a specificity to one of the lectins listed above.

\section{DISCUSSION}

The present work confirms that under laminar conditions biofilms are thicker, as expected from the reduced shear stress effects and from the absence of turbulent eddies. Also, as often succeed, these biofilms present substantial fluctuations in their thickness and mass over time (Table I and Fig. 4) due to sloughing off and regrowth. They are known to be less dense (more "fluffy") than biofilms formed under turbulent flow conditions (Characklis and Marshall, 1990; Wijeikoon et al., 2000) and, thus, with less resistance to detachment. On the other hand, higher flow rates give rise to denser biofilms strongly adhered to the surface, as previously reported (Vieira et al., 1993, Wijeikoon et al., 2000). This explains the more stable trend of the biofilm growth curve obtained under turbulent flow (Fig. 4).

The higher cell density per unit area in the upper layers of both biofilms (Fig. 3) is not in accordance with the results from a few investigations carried out under laminar flow with $P$. fluorescens biofilms, where the highest density of cells was found near the substratum (Lawrence et al., 1987; Lawrence and Korber, 1993; Kuehn et al., 1998). However, other authors (Neu and Lawrence, 1997) reported that in raw river water, biofilms containing colloidal debris the highest cell density was located in the outer region of the biofilm at some distance from the substratum. The fact that in the present work the velocities were significantly higher than in the above mentioned studies with $P$. fluorescens (5 to 20 times), resulted in a much greater rate of substrate transport from the fluid to the biofilm surface, which should favour the presence of a high number of active bacteria in the upper layers of the film.

Although under laminar conditions the biofilm contained more cells than under turbulent flow (the total mass was higher too), there were more cells per unit wet volume in the biofilm formed under turbulent condi- tions. This gives an idea of how the cells build their habitat when subject to stronger hydrodynamic stresses: it can be assumed that they produce more exopolymers per unit volume to create an effective adhesion and, at the same time, reduce the void fraction in the biofilm (lower thickness, higher density) to impart a greater cohesion to the biological matrix. In this way, the cells manage to remain relatively active within the matrix, but protected from external aggressions. Although it was not possible to identify the exopolymers by staining procedures, greater amounts of extra cellular polymeric substances (EPS) were observed in the scanning electron microscope in the biofilm formed under turbulent regime than under laminar regime: the polymeric viscous material is much more clearly seen in Figure 5b (turbulent flow) than in 5a (laminar flow).

The data shown in Table II corroborate previous assumptions made by Melo and Vieira (1999) about the different layers formed during biofilm growth, as regards

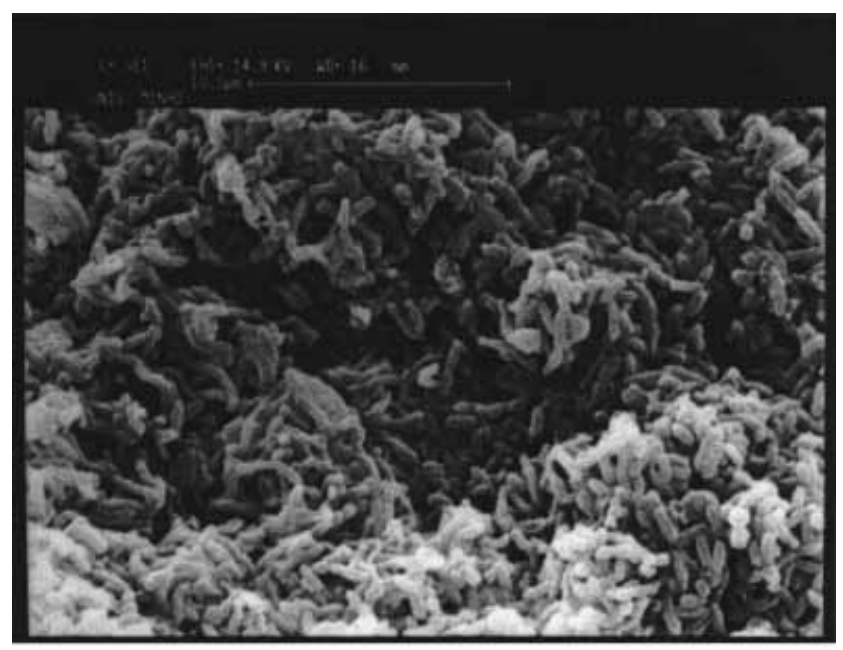

(a)

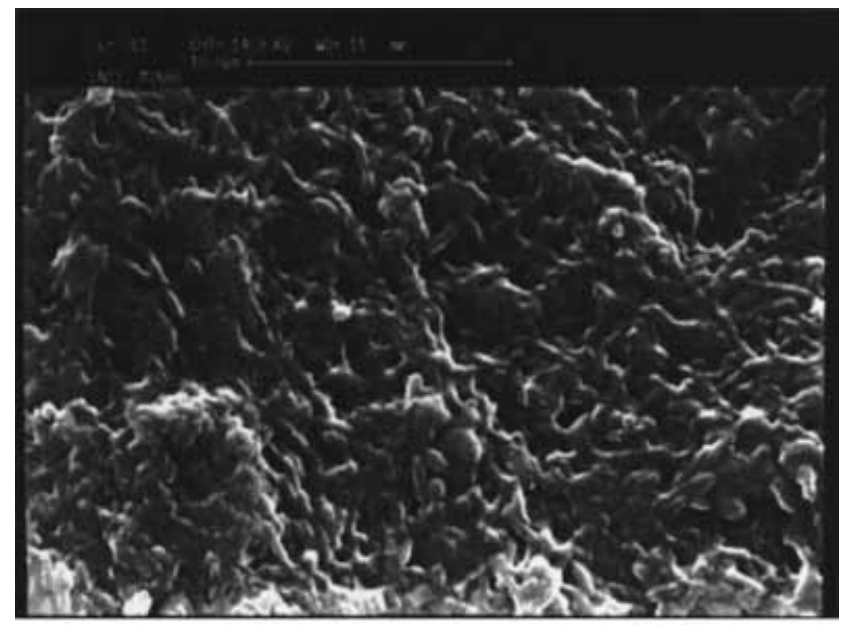

(b)

Figure 5. SEM photomicrographs of a 10-day-old Pseudomonas fluorescens laboratory biofilms formed on stainles-steel slides under laminar (a) turbulent (b) conditions. $\times 3900$ magnification, bar $=10 \mu \mathrm{m}$. 
to the relationship between cell mass and exopolymer mass. They postulated that the rate of increase in cell mass within a biofilm is smaller than the rate of growth of the total biofilm dry mass. This is due to the fact that each cell utilizes the substrate with (at least) two different purposes: to reproduce itself and to produce extracellular polymers. Therefore, from the initial layers to the final upper layers of the biofilm (or biomass cluster), the fraction of cells in the total dry biomass will become progressively smaller, because the exopolymeric part of the attached biomass does not produce new cells. That assumption had already been verified in an indirect way, by fitting the resulting mathematical model to the growth curves of different biofilms formed under turbulent flow (Melo and Vieira, 1999).

The results presented in this work indicate, however, that this concept cannot yet be clearly confirmed in laminar flow situations, because of the disturbances introduced by the substantial biomass losses due to uneven detachment (sloughing off) during biofilm development. Although the data in Table II may seem, at first sight, in contradiction with the cell distribution shown in Figure 3, they are not comparable. The latter refers to the cell distribution in different biofilm layers at a given instant of time (without relating it to the overall biofilm mass), while Table II indicates the average cell fraction in the whole biofilm mass at different time points of biofilm formation.

\section{CONCLUSIONS}

The following main conclusions can be drawn from the present study performed with a single species biofilm under laminar and turbulent flow conditions (care should be taken in extrapolating these conclusions to the case of multi-species, multi-substrate biofilms): 1) Biofilms formed under laminar flow regime are thicker, less dense, and contain a higher total number of cells than similar (same species) biofilms formed under turbulent regime; 2) The upper layers of the biofilms contain more cells than the inner layers, regardless of the flow regime under which the microbial films were formed; 3) The mass of biofilms in contact with laminar flows is subject to more pronounced fluctuations and has a lower concentration of cells per unit volume of wet biofilm; 4) The results from Table II confirm the assumption that the number of microorganisms in a developing biofilm does not increase proportionally to the biofilm dry mass (cell + exopolymers), i.e., the fraction of cells in the dry mass of biofilm should decrease over time during the growth of the microbial film. Such an assumption was previously proposed in the development of a model for the prediction of the biofilm final thickness (Melo and Vieira, 1999), which is needed for the application of the diffusion-reaction models used in biofilm reactor design.

The results from the present work suggest that wastewater treatment reactors started and operated under turbulent flow will be less affected by hydraulic changes occurring during their operation and can be made more compact than reactors operating with laminar flow streams (for the same substrate consumption rate). The decrease in the mass fraction of cells as the thickness increases seems also to favour the operation of wastewater treatment reactors with relatively thin biofilms. Therefore, if diffusional limitations in the thinner and denser biofilms formed under turbulent flow conditions do not prevail, then those reactors can also be more efficient in terms of substrate consumption rate. This concept has been applied to the design of new biofilm reactors in recent years (Tijhuis et al., 1992; Lazarova and Manem, 2000).

The access to the CLSM by Werner Zuschratter is highly appreciated.

\section{References}

Azeredo JA, Lazarova V, Oliveira R. 1999. Methods to extract the exopolymeric matrix from biofilms: a comparative study. Wat Sci Tech 39:243-250.

Bott TR. 1995. Fouling of Heat Exchangers. Amsterdam: Elsevier. $524 \mathrm{pp}$.

Brading MJ, Boyle J, Lappin-Scott HM. 1995. Biofilm formation in laminar flow using Pseudomonas fluorescens EX101. J Industrial Microbiol 15:297-304.

Characklis WG, Marshall KC. 1990. Biofilms. New York: John Wiley and Sons. 796 pp.

Daniel WW. 1987. Biostatistics: a foundation for analysis in the health sciences. New York: Wiley and Sons. 747 pp.

de Beer D, Schramm A. 1999. Micro-environments and mass transfer phenomena in biofilms studied with microsensors. Wat Sci Tech 39:173-178.

Kuehn M, Hausner M, Bungartz H-J, Wagner M, Wilderer PA, Wuertz S. 1998. Automated confocal laser scanning microscopy and semiautomated image processing for analysis of biofilms. Appl Environ Microbiol 64:4115-4127.

Lewandowski Z, Stoodley P. 1995. Flow induced vibrations, drag force, and pressure drop in conduits covered with biofilm. Wat Sci Tech 32:19-26.

Lawrence JR, Delaquis PJ, Korber DR, Caldwell. 1987. Behaviour of Pseudomonas fluorescens within the hydrodynamic boundary layers of surface microenvironments. Micro Ecol 14:1-14.

Lawrence JR, Korber DR. 1993. Aspects of microbial surface colonization behaviour. In: Guerrero R, Pedros-Alio, editors. Trends in microbial ecology. Barcelona: Spanish Society for Microbiology. p 113-118.

Lawrence JR, Neu TR, Swerhone GDW. 1998a. Application of multiple parameter imaging for the quantification of algal, bacterial, and exopolymer components of microbial biofilms. J Microbiol Methods 32:253-261.

Lawrence JR, Wolfaardt G, Neu TR. 1998b. The study of microbial biofilms by confocal laser scanning microscopy. In: Wilkinson MHF, Shut F. editors. Digital image analysis of microbes. Chichester: John Wiley. p 431-465.

Lawrence JR, Neu TR. 1999. Confocal laser scanning microscopy for analysis of microbial biofilms. Methods Enzymol 310:131144.

Lawrence JR, Korber DR, Wolfaardt GM, Caldwell DE, Neu TR. 2001. Analytical imaging and microscopy techniques. In: Hurst CJ, Knudsen GR, McInerney MJ, Stetzenbach LD, Walter MV, 
editors. Manual of environmental microbiology. Washington: American Society for Microbiology. 50 pp., 2nd edition.

Lazarova V, Manem J. 2000. Innovative biofilm treatment technologies for water and wastewater treatment. In: Bryers JD, editor. Biofilms II: Process analysis and applications. New York: WileyLiss, Inc.

Melo L, Vieira MJ. 1999. Physical stability and biological activity of biofilms under turbulent flow and low substrate concentration. Bioproc Eng 20:363-368.

Neu TR, Lawrence JR. 1997. Development and structure of microbial biofilms in river water studied by confocal laser scanning microscopy. FEMS Microbiol Ecol 24:11-25.

Okabe S, Kuroda H, Watanabe Y. 1998. Significance of biofilm structure on transport of inert particulates into biofilms. Wat Sci Tech 38:163-170.

Oliveira R, Melo L, Oliveira A, Salgueiro R. 1994. Polysaccharide production and biofilm formation by Pseudomonas fluorescens: effects of $\mathrm{pH}$ and surface material. Coll Surf. B Biointerfaces 2:41-46.
Peyton BM. 1996. Effects of shear stress and substrate loading rate on Pseudomonas aeruginosa biofilm thickness and density. Wat Res 30:29-36

Sanford BA, Feijter AW, Wade MH, Thomas VL. 1996. A dual fluorescence technique for visualization of Staphylococcus epidermidis biofilm using scanning confocal laser microscopy. J Ind Microbiol 16:48-56.

Schlichting. 1979. Boundary layer theory. New York: McGraw-Hill Book Company. 817 pp.

Tijhuis L, van Loosdrecht MCM, Heijnen JJ. 1992. Nitrification with biofilms on small suspended particles in airlift reactors. Wat Sci Tech 26:2207-2221.

Vieira MJ, Melo LF, Pinheiro MM. 1993. Biofilm formation: hydrodynamic effects on internal diffusion and structure. Biofouling $7: 67-80$.

Wijeyekoon S, Mino T, Satoh H, Matsuo T. 2000. Growth and novel structural features of tubular biofilms produced under different hydrodynamic conditions. Wat Sci Techn 41:129-138. 